\title{
Cross-shore suspended sediment transport in the surf zone: a field-based parameterization
}

\author{
Troels Aagaard ${ }^{\mathrm{a}, *}$, Kerry P. Black ${ }^{\mathrm{b}}$, Brian Greenwood ${ }^{\mathrm{c}}$ \\ a Institute of Geography, University of Copenhagen, Oster Voldgade 10, DK-1350 Copenhagen K., Denmark \\ b ASR Ltd., Marine and Freshwater Consultants, P.O. Box 13048, Hamilton, New Zealand \\ c Department of Geography, The University of Toronto at Scarborough, 1265 Military Trail, Scarborough, ON, Canada M1C $1 A 4$
}

Received 21 June 2001; accepted 4 February 2002

\begin{abstract}
Existing cross-shore sediment transport models for two-dimensional surf zone bathymetries almost invariably predict offshore-directed sand transports and bar migrations during storm conditions. However, onshore-directed suspended sediment fluxes and associated nearshore bar migration were observed during recent field experiments on a gently sloping beach on the Danish North Sea coast. Field measurements of suspended sediment flux obtained during three experiments on two different beaches are used to parameterize the observed fluxes. This parameterization predicts suspended sediment transport due to incident waves and undertow across bars in two-dimensional surf zones. First, a non-dimensional sediment flux index is formulated which describes the tendency towards net onshore or offshore transport and the strength of that tendency. The non-dimensional formulation circumvents the problem of measurement inconsistencies due to varying elevations of sediment concentration sensors relative to the bed. The index is found to depend upon the undertow velocity, the incident wave skewness and the cross-correlation between orbital velocity and sediment concentration. However, some of these parameters are difficult to predict, particularly in barred surf zones and therefore, the independent variables are recast in terms of a set of more easily obtainable parameters. The sediment flux index depends on a combination of the following: non-dimensional bed shear stress (the Shields parameter), relative water depth, wave orbital velocity, relative wave height and bed slope. Finally, a formulation of suspended sediment transport across bars is obtained by linking the flux index with a parameterization of the sediment concentration/distribution in the water column. These concentrations are found to depend on nondimensional bed shear stress, relative wave height and water depth. The formulation predicts a tendency for onshoredirected sediment transport due to incident waves on gently sloping beaches and/or with large bed shear stresses. On steeply sloping beaches and/or in the inner part of the surf zone there is a tendency towards offshore sediment transports due to the undertow. (c) 2002 Elsevier Science B.V. All rights reserved.
\end{abstract}

Keywords: sediment transport; sediment concentrations; incident waves; undertow; morphodynamics; beach processes

* Corresponding author. Fax: +45-3532-2501.

E-mail address: taa@geogr.ku.dk (T. Aagaard).

\section{Introduction}

Considerable effort has been spent within coastal science and engineering towards predicting the direction and magnitude of sediment transport in 
the surf zone, and the ensuing morphological response. While relatively robust models exist for the prediction of longshore sediment transport, this is not the case for the cross-shore component which is generally responsible for beach profile change. A major reason for this lack of predictive capability is that several mechanisms contribute to the transport, including mean currents and oscillatory waves at incident and infragravity frequencies (e.g. Osborne and Greenwood, 1992; Aagaard and Greenwood, 1994; Ruessink et al., 1998; Aagaard et al., 1998; Russell and Huntley, 1999). The relative importance and directional attributes of these components will determine the magnitude (and direction) of the net transport. There is a general consensus that in cases when waves are breaking, the sediment transport tends to be directed offshore, due to the seaward-directed undertow generated by wave breaking and radiation stress decay. The ensuing profile response is a seaward migration of nearshore bars. During non-breaking wave conditions, the transport is assumed to be onshore-directed, due to the effects of incident wave skewness/asymmetry driving nearshore bars landward (e.g. Shepard, 1950; Birkemeier et al., 1997; Komar, 1998; Lee et al., 1998; Elgar et al., 2001).

Osborne and Greenwood (1992) attempted to parameterize suspended sediment transport directions in the field using local values of the relative wave height $\left(H_{\mathrm{s}} / h\right.$, where $H_{\mathrm{s}}$ is significant wave height and $h$ is water depth), while Ruessink et al. (1998) used an extensive data set to conclude that the net sediment transport direction in the nearshore indeed appeared to be a function of $H_{\mathrm{s}} / h$. Under non-breaking conditions, transport rates were small, while breaking waves $\left(H_{\mathrm{s}} / h>\right.$ $\approx 0.33$ ) induced a significant offshore-directed net transport due to both undertow and groupbound long waves.

A fairly large number of numerical models and algorithms exist for prediction for cross-shore sediment transport in two-dimensional bathymetric settings. Tests of the Bailard energetics model (Bailard, 1981) using measured velocity time series (Thornton et al., 1996; Gallagher et al., 1998) or time-averaged quantities of velocity moments (Russell and Huntley, 1999) yield predictions of offshore sediment transport landward of the breakpoint and onshore transport outside the breakpoint. Landward of the breakpoint, the SBEACH model (Larson and Kraus, 1989) predicts offshore-directed sediment transport due to the undertow, if wave dissipation is larger than some critical value, and zero transport otherwise. Surf zone sediment transport directions and rates predicted by the CROSMOR model (Van Rijn, 1993, 1998) depend on a balance between predicted undertow velocity and higher-order velocity moments and generally produces offshore-directed transports and offshore bar migration landward of the wave breakpoint (Grasmeijer et al., 1999; Van Rijn et al., 1999). Field tests revealed a tendency towards overpredicting wave skewnesses and undertow velocities in the surf zone (Grasmeijer and van Rijn, 1999). A common characteristic of these models is that they assume a zero lag between wave orbital velocity and nearbed sediment concentration and they predict fairly well offshore-directed sediment transport rates due to the undertow in the case of breaking waves, whereas there are difficulties with predicting the (necessary) onshore-directed transports under non-breaking (or breaking) wave conditions (Schoonees and Theron, 1995; Thornton et al., 1996; Miller et al., 1999). Recently, some progress may have been made using a phase-resolving intra-wave model (Rakha et al., 1997) which seems to be able to yield realistic onshore-directed transports outside laboratory surf zones and also at some locations inside the breaker zone. This model is, however, rather complicated and difficult to apply.

Hence, a general characteristic of these parameterizations and models is that they, perhaps except for the latter reference, consistently predict offshore-directed sediment transports and nearshore bar migration within the surf zone. This may cause problems when they are applied to natural surf zones. One problem is that surf zone morphology in the field may be strongly three-dimensional with crescentic bars and horizontally segregated mean flows involving rip currents. Such conditions can introduce strong morphodynamic feedbacks between the morphology and the hydrodynamics; in this case the profile 
response displays a spatial variability and bars frequently move onshore even under breaking wave conditions (Greenwood and Davidson-Arnott, 1979; Wright and Short, 1984; Aagaard et al., 1998; Ruessink and Terwindt, 2000). Furthermore, even in the case of a two-dimensional bathymetry, i.e. with straight shore-parallel nearshore bars and a vertically segregated mean current (undertow) circulation and thus under conditions when the models would be expected to apply, bars within a high-energy surf zone have been observed to move onshore during intense storms, driven by landward-directed suspended sediment fluxes at incident wave frequencies (Aagaard and Greenwood, 1999). Such onshore-directed sediment transports under breaking waves were also observed by Ruessink et al. (1998) and Miller et al. (1999), but not explained.

The present study was motivated by the observations of divergent sediment flux directions and morphological behavior under seemingly similar wave energy conditions on two different beaches on which the mean current circulation was characterized by vertically segregated mean flows. In order to attempt a reconciliation of these conflicting observations, the present paper proposes an empirical process-based formulation of crossshore suspended sediment transport under breaking waves for two-dimensional bathymetries.

Field data were collected from three experiments on two distinctly different beaches and under a wide range of incident wave energy conditions (breaker heights $H_{\mathrm{b}} \approx 0.2-2.8 \mathrm{~m}$ ). First, a non-dimensional cross-shore sediment flux index is formulated, indicating the direction of the net sediment flux close to the bed. This index is shown to depend upon a number of hydrodynamic and sediment dynamic process parameters that are difficult to predict a priori. The process parameters are therefore recast in terms of a set of hydrodynamic, textural and bathymetric properties in order to obtain a parameterization of the directional characteristics of the sediment flux in the near-bed layer. Then, sediment concentrations in the near-bed layer are parameterized using the same field data sets and finally combined with the flux direction index to obtain a first approximation of cross-shore near-bed sediment transport rates across nearshore bars under breaking wave conditions.

\section{Field sites}

Field work was conducted on two distinctly different beaches in terms of profile configuration. The Skallingen field site is located on the Danish North Sea coast. It is a dissipative beach exposed to wind-generated waves from predominantly southwesterly and westerly directions. Fetches are relatively long and during storms, offshore wave heights may exceed $5 \mathrm{~m}$, with peak spectral periods of 10-13 s. Low-energy swell may persist for a couple of days after storms and the mean annual significant wave height is on the order of $0.5-0.6 \mathrm{~m}$.

The nearshore is gently sloping $(\beta \approx 0.007)$ with an intertidal slope of $\beta \approx 0.02-0.03$. The mean grain size in the surf zone is $150-200 \mu \mathrm{m}$ and the cross-shore profile exhibits two to three subtidal (nearshore) bars as well as a highly mobile intertidal (swash) bar, see Fig. 1. During high-energy events, depth-limited wave breaking usually commences some distance seaward of the bars and persists continuously from the middle bar to the shoreline. The beach experiences a low-mesotidal regime with a spring tidal range $(T R)$ of about $1.8 \mathrm{~m}$. The gentle slopes (horizontal shoreline excursion at spring tides: $T R / \beta \approx 75 \mathrm{~m}$ ), and the fact that the site is frequently subjected to storm surges, enhance the effects of water level fluctuations. Moderate storms typically result in surges of $\pm 0.5 \mathrm{~m}$, depending on wind direction, while severe (onshore) storms may elevate astronomically predicted tide levels by up to $3 \mathrm{~m}$.

Data from two field experiments at Skallingen, which were conducted in the fall of 1995 and 1996 are included here. During the first part of the 1995 experiment (SK95), the morphology was characterized by almost straight bars dissected by rip channels and distinct horizontally segregated cell circulations occurred (Aagaard et al., 1998). During the latter part of SK95 as well as during the 1996 experiment (SK96), bars were two-dimensional and vertically segregated offshore-directed mean flows (undertows) occurred 


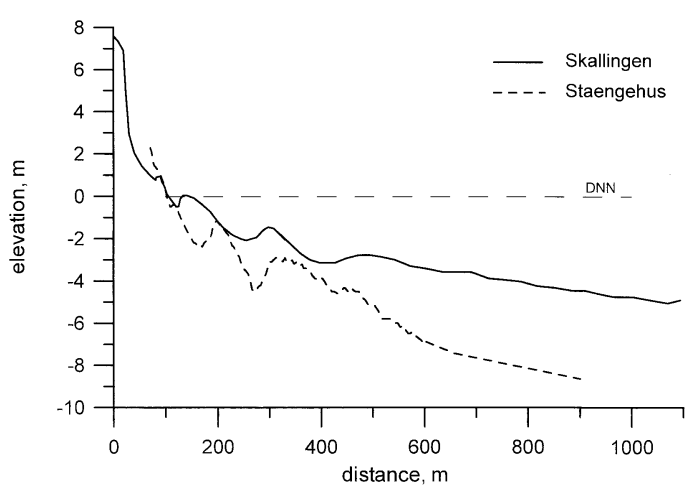

Fig. 1. Cross-shore profiles at Skallingen (solid line) and at Staengehus (dashed line). DNN is Danish Ordnance Datum.

whereas rip currents were absent. Only data from these two-dimensional bathymetric situations with an undertow circulation are considered in this paper and these are the conditions that most sediment transport/morphodynamic models attempt to simulate.

The second field site was the modally intermediate-state beach at Staengehus on the north coast of Zealand, Denmark. The site is exposed towards the northwest and the wave climate at the locality is highly variable. As the beach faces into the direction of the strongest winds and fetches are relatively short $(\leq 150 \mathrm{~km})$, brief storm events with breaker heights over the outer bar up to $2-2.5 \mathrm{~m}$ and peak spectral wave periods of 5-7 s are interspersed with lengthy and relatively calm periods. Long-period swell energy is insignificant. The beach is virtually tideless with spring tidal ranges of the order of $0.2-0.3 \mathrm{~m}$. Surges up to $0.5 \mathrm{~m}$ occur during lengthy northwesterly storms.

The slope of the nearshore at Staengehus is twice as steep as at Skallingen $(\beta \approx 0.016)$ and exhibits three nearshore bars (Fig. 1). Bar relief is significantly larger than at Skallingen and waves tend to reform in troughs between bars even under storm conditions. The mean sand grain size on the bars is typically $200-250 \mu \mathrm{m}$ while the sand has been winnowed away and gravels and boulders are exposed in the troughs between bars. During the field experiment conducted during the fall of 1998, the two inner bars were weakly crescentic, but no rip circulations were observed at any time.

\section{Instrumentation}

Measurements at the two sites consisted of waves, currents and sediment fluxes being recorded in cross-shore transects across the inner nearshore zone, using arrays of electromagnetic current meters (Marsh McBirney OEM512), pressure sensors (Viatran Model 240) and optical backscatter sensors (D\&A Instruments OBS-1P). Five/six and eight instrument stations were used, respectively, at Skallingen and at Staengehus (Fig. 2). Instruments were mounted on $\mathrm{H}$-frames with the sensors (except for the pressure transducers) being suspended from the cross-pieces of the frames. The horizontal distance between the current meters and the backscatter sensors was approximately $0.25 \mathrm{~m}$.

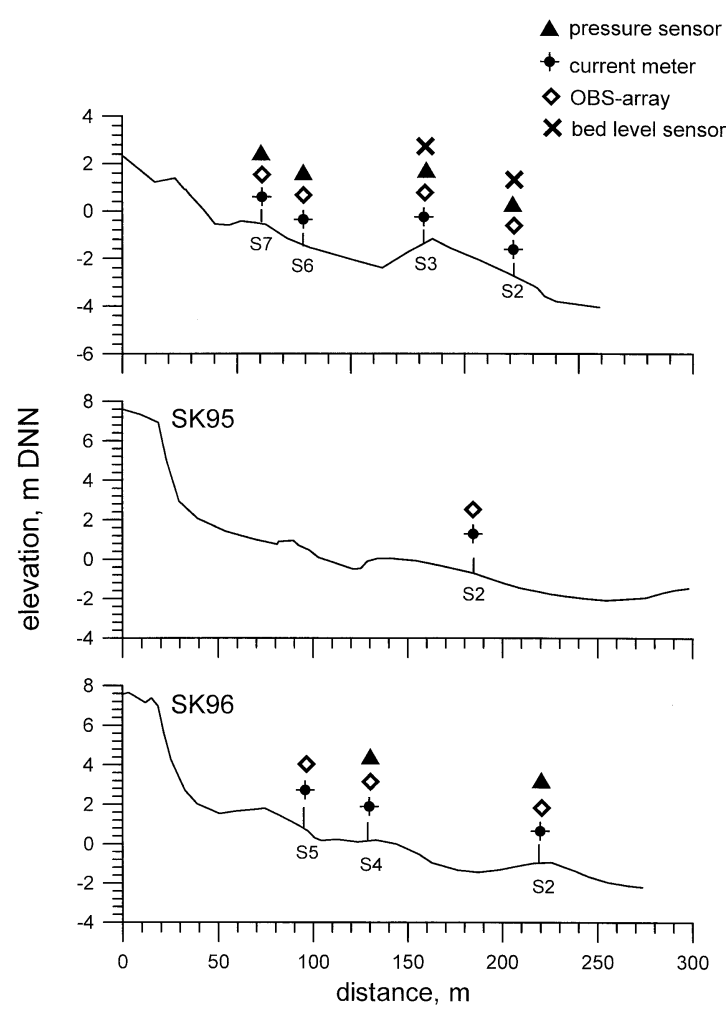

Fig. 2. Cross-shore profiles of the inner nearshore during the three field experiments at Staengehus (STG98) and Skallingen (SK95, SK96). Sensor locations and instrument station designations are indicated. Only stations mentioned in the text have been shown. 
The optical backscatter sensors were deployed at nominal elevations of $z=0.05,0.10$ and $0.20 \mathrm{~m}$, and current meters were mounted at $z=0.20-0.30$ $\mathrm{m}$. While the OBS were deployed as close to the bed as possible to capture significant sediment suspensions, the current meters were kept further away in order to minimize the risk of burial or signal distortion from the boundary. At Skallingen, instrument elevations were recorded and adjusted at each low tide, whenever possible, to compensate for bed level changes. Between low tides, sensor elevation was interpolated. At Staengehus, the surf zone was inaccessible during periods of high energy and sensors could not be adjusted. However, at stations S2 and S3 (Fig. 2), bed elevation sensors (Ridd, 1992; Aagaard et al., 2001) were installed approximately $1 \mathrm{~m}$ away from the backscatter array. These sensors continuously recorded the elevation of the bed such that a rough estimate of OBS and current meter elevations at these positions could be obtained.

All sensors were hardwired to shore-based data acquisition systems and sampled at $4 \mathrm{~Hz}(10 \mathrm{~Hz})$ for 34.1 (45) min at Skallingen (Staengehus) with a duty cycle of $1 \mathrm{~h}$ during storm events. Pressure sensors and current meters were calibrated prior to deployment. Field offsets were checked repeatedly in buckets and during still water conditions. The optical backscatter sensors were gain-calibrated in a recirculating tank after the experiments using sand from the deployment locations, while field offsets due to more or less permanently suspended organics and/or silt and clay particles were determined for individual records using the fifth percentile frequency output voltage (see Aagaard and Greenwood, 1994). Finally, sediment samples were taken at all instrument stations for subsequent laboratory analysis and determination of grain size parameters.

\section{Data analysis}

Instrument outputs were screened and inspected visually to check data quality. Noisy and/or erroneous data e.g. due to instrument proximity to the bed, or burial were dismissed from further analy- sis. At Staengehus, seaweed was a frequent problem that manifested itself as large increases in, or saturation of OBS signals for lengthy periods of time. Current meters were also occasionally affected by this problem, resulting in significantly decreased sensor outputs usually occurring simultaneously with backscatter problems. Records containing evidence of such problems were also discarded.

Surface elevation spectra were computed from pressure records and corrected for frequencydependent depth attenuation using linear wave theory over the frequency range $0-0.5 \mathrm{~Hz}$. Due to amplification of noise at high frequencies, an upper limit frequency cut-off was determined as:

$\omega_{\mathrm{c}}=0.564 \pi(g / d)^{0.5}$

(Green, 1999) where $\omega$ is radian frequency $(2 \pi / T)$, $g$ is the acceleration due to gravity and $d$ is depth of submergence of the pressure sensor. Rootmean-square (rms) wave heights were computed as:

$H_{\mathrm{rms}}=\sqrt{8}\left(\sum_{0}^{\omega_{\mathrm{c}}} S_{\mathrm{s}}(f)\right)^{0.5}$

where $S_{\mathrm{s}}$ is surface elevation spectral density and significant wave heights were determined as $H_{\mathrm{s}}=\sqrt{2} H_{\mathrm{rms}}$. Wave heights at stations lacking pressure sensors were estimated from current meter variance using the linear transfer function:

$H_{\text {rms }}=\sqrt{8}\left(<\sigma^{2}>h / g\right)^{0.5}$

where $\sigma^{2}$ is velocity variance and $h$ is water depth.

The magnitude and skewness of wave orbital velocities are generally considered to be of critical importance to the direction and magnitude of the incident wave-driven sediment flux (e.g. Bailard, 1981; Thornton et al., 1996; Gallagher et al., 1998; Van Rijn, 1998). Oscillatory velocities were demeaned and separated into infragravity and incident wave band contributions using Fourier filtering techniques and a separation frequency of $0.067 \mathrm{~Hz}$. Cross-shore incident wave skewness 
was quantified by:

$S=\frac{\left(u_{\mathrm{c}}^{3}-u_{\mathrm{t}}^{3}\right)}{\left(u_{\mathrm{c}}^{3}+u_{\mathrm{t}}^{3}\right)}$

(Van Rijn, 1993; Aagaard and Greenwood, 1999) where $u_{\mathrm{c}}, u_{\mathrm{t}}$ are the high-pass filtered maximum oscillatory velocities at wave crests and wave troughs, respectively. In the present data set, incident wave skewnesses were always positive, i.e. directed landward.

In the calculations of suspended sediment fluxes, data from bar crests and the upper seaward slopes of the bars were selected for analysis. This is where wave energy levels and consequently bed shear stresses are the largest, generally resulting in the largest sediment concentrations and gross (but not necessarily net) transport rates (e.g. Aagaard et al., 1998; Ruessink et al., 1998). Furthermore, vortex ripples which complicate the phase relationships between velocity and concentration (Osborne and Greenwood, 1993) are absent at times of high energy. Finally, cross-shore transport at such positions should reflect the migration of bars and thus the general morphological evolution of the profile. Data from S2 (Skallingen) and S2, S3, S6 and S7 (Staengehus), see Fig. 2, have been selected for the sediment transport analysis.

The present analysis is generally restricted to the effects of incident waves and mean currents, and sediment fluxes due to oscillatory infragravity motions were ignored. Infragravity wave fluxes display spatially and often temporally varying directional characteristics in the surf zone (Aagaard and Greenwood, 1994; Thornton et al., 1996; Gallagher et al., 1998) and at the instrument locations selected they contributed less than $20 \%$ of the gross sediment flux, on average (Aagaard and Greenwood, 1999). Only at station S7 (Staengehus) did their contribution sometimes exceed 30\% during an individual run. Such ratios are significantly smaller than values obtained close to the shoreline/in the intertidal zone (e.g. Beach and Sternberg, 1991; Russell, 1993; Aagaard, 2001) but agree with ratios reported by Ruessink et al. (1998) for positions in the nearshore.

Finally, only data obtained under surf zone conditions were used. The offshore extent of the surf zone was determined from the local values of the relative wave height. Visual observations and wave height records from these two sites indicate that wave breaking is initiated for a local relative wave height of $H_{\mathrm{s}} / h \geq 0.35$ and most waves break for $H_{\mathrm{s}} / h \geq 0.40$. Wave heights saturate for $H_{\mathrm{s}} / h$ $\approx 0.60$ (e.g. Thornton and Guza, 1982; Wright et al., 1982; Sallenger and Holman, 1985) and here, this value has been used to separate the inner and the outer surf zones.

Net suspended sediment flux at a point was computed as the cross-product of instantaneous velocity $(u)$ and sediment concentration $(c)$ :

$\left\langle q_{\mathrm{s}}\right\rangle=\frac{1}{n} \Sigma u c$

where $n$ is the number of data points in the sample and \langle\rangle denotes the time average. Following Jaffe et al. (1984) and Huntley and Hanes (1987), the net flux was separated into a mean and an oscillatory term:

$\left\langle q_{\mathrm{s}}\right\rangle=\bar{u} \bar{c}+u^{\prime} c^{\prime}$

where the first term on the right-hand side of the equation is suspended sediment flux due to mean currents which was always negative, i.e. directed offshore for the present data set. The second term in Eq. 6 is the flux coupling (i.e. the covariance) between oscillatory wave motions and sediment concentration. This term was generally positive at incident wave frequencies, i.e. onshore-directed. Information on transport magnitude and direction across frequency space was obtained by plotting the cospectra of velocity and concentration:

$u^{\prime} c^{\prime}=\frac{\Delta f}{F} \int_{0}^{T} C_{u c}(f) \mathrm{d} t$

where $C_{u c}(f)$ is cospectral density at a frequency $f$, $\Delta f$ is cospectral resolution and $F$ cospectral frequency range, in this case 2 or $5 \mathrm{~Hz}$. Sediment flux contributions from incident and infragravity waves were separated at a frequency of $0.067 \mathrm{~Hz}$.

Sediment fluxes at a given station were eval- 
uated using the lowermost exposed OBS sensor in an array. Integrations over an instrument array were not attempted because: (a) sometimes only one or two sensors in an array were exposed and/ or functioned properly, (b) under the (relatively high) energy surf zone conditions sampled here, the bed was probably flat and phase lags between velocity and sediment concentration were small (see below); consequently directional flux reversals in the vertical were extremely rare, and (c) sediment concentrations increase towards the bed and the lowermost (exposed) OBS is considered being more representative for the bulk sediment transport.

\section{Results}

\subsection{Observations}

Fig. 3 illustrates net sediment fluxes recorded at bar crests (stations S3 at Staengehus and S2 at Skallingen) during a number of storm events. Off-

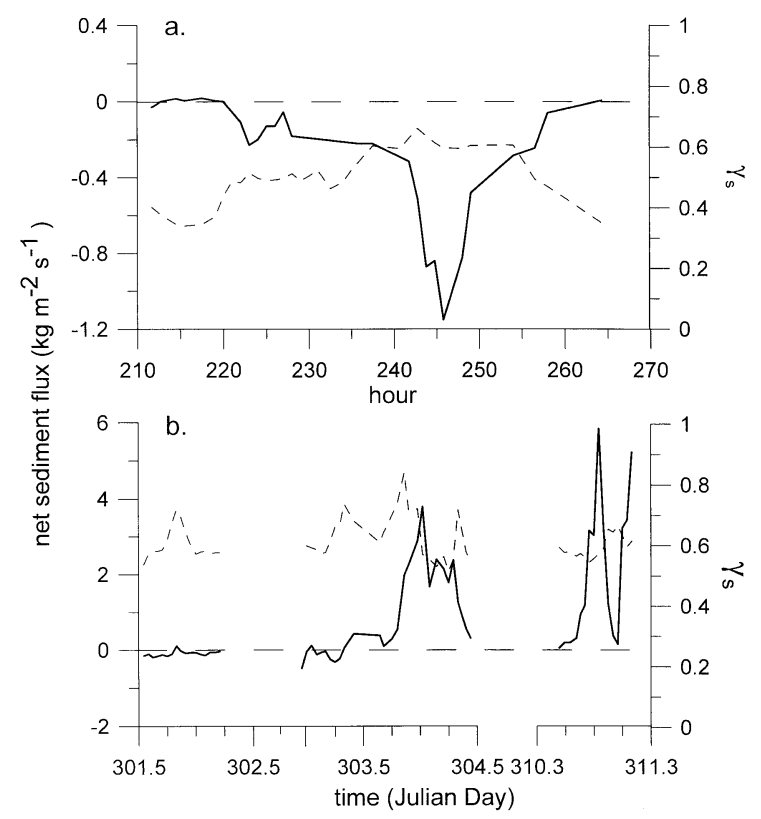

Fig. 3. Net cross-shore suspended sediment fluxes (solid lines) recorded at (a) Staengehus (station S3) and (b) Skallingen (SK96; station S2). Positive fluxes are onshore-directed. The dashed lines indicate the local relative wave height, $\gamma_{\mathrm{s}}\left(=H_{\mathrm{s}} /\right.$ h). Wave heights are saturated for $\gamma_{\mathrm{s}} \approx 0.60$. shore wave conditions for these particular events were similar with significant wave heights peaking at $1.9 \mathrm{~m}$ (Staengehus) and 1.9, 1.8 and $2.3 \mathrm{~m}$, respectively, for the three events at Skallingen. Local relative wave heights $\left(H_{\mathrm{s}} / h=\gamma_{\mathrm{s}}\right)$ exceeded 0.60 at times of high wave energy and bar crests were therefore located in the inner surf zone at such times. Even so, the net sediment fluxes were directed offshore (negative values) at Staengehus while they were onshore (positive) for two of the three events at Skallingen. As most sediment transport models would predict offshore-directed sediment transports under such inner surf zone conditions, explanations of these contrasting observations would seem to be required.

In Fig. 4, the net fluxes are partitioned into contributions from the undertow and waves at incident and infragravity frequencies. The two major transport mechanisms were the undertow, providing an offshore-directed sediment flux, and the incident waves which are responsible for onshore fluxes. It is evident that at these positions, infragravity motions were of secondary importance to the sediment flux.

\subsection{A sediment flux index}

When using backscatter sensors for measuring sediment concentrations in the field, uncertainties are introduced in such measurements and in estimates of suspended sediment flux, because of the variable elevations of the backscatter sensors relative to the bed, which is caused by bed erosion and accretion. Fluxes are therefore difficult to compare spatially and temporally. In an attempt to reduce this problem, a normalized sediment flux index, reflecting the sediment transport direction, $Q_{\mathrm{d}}$ is formulated as:

$Q_{\mathrm{d}}=\frac{\left\langle q_{\text {inc }}\right\rangle+\left\langle q_{\text {mean }}\right\rangle}{\left|\left\langle q_{\text {inc }}\right\rangle\right|+\left|\left\langle q_{\text {mean }}\right\rangle\right|}$

where $\left\langle q_{\text {inc }}\right\rangle,\left\langle q_{\text {mean }}\right\rangle$ are the time-averaged magnitudes of suspended sediment flux due to oscillatory incident waves and to mean currents, respectively, and contributions from infragravity waves have been ignored. Under the present conditions 


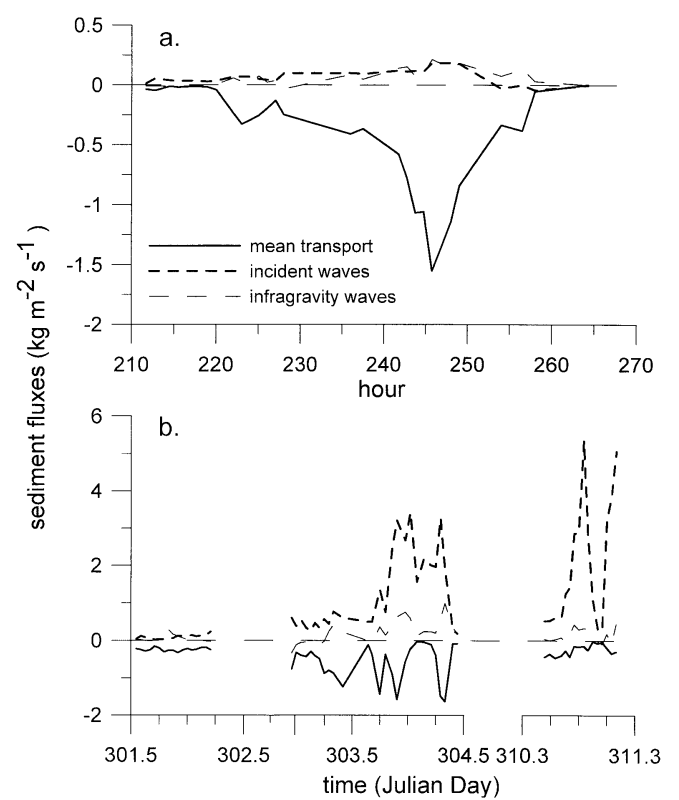

Fig. 4. Partitioned suspended sediment fluxes due to mean flows, incident and infragravity waves at (a) Staengehus (station S3) and (b) Skallingen (SK96; station S2). Positive fluxes are directed onshore.

when rip currents were absent, the mean currents were due to undertow, i.e. directed offshore (negative). Oscillatory sediment fluxes at incident wave frequencies, in contrast, were onshore-directed (positive) when waves were breaking (Figs. 3 and 4). Hence, the net sediment flux will be increasingly dominated by incident wave motions and directed onshore when $Q_{\mathrm{d}}$ attains positive values, and increasingly dominated by the mean component and directed offshore when $Q_{\mathrm{d}}$ becomes negative. When $Q_{\mathrm{d}}=0$, the contributions from incident waves and undertow are in balance and the profile should approximate a local equilibrium (apart from perturbations introduced by infragravity waves, gravity and bedload).

\subsection{Sediment flux directions in the surf zone}

In Fig. 5, net suspended sediment fluxes (including the contribution from infragravity oscillations) measured at Staengehus and Skallingen have been plotted as a function of the local relative wave height, $H_{\mathrm{s}} / h$, which was used by Osborne and Greenwood (1992) and Ruessink et

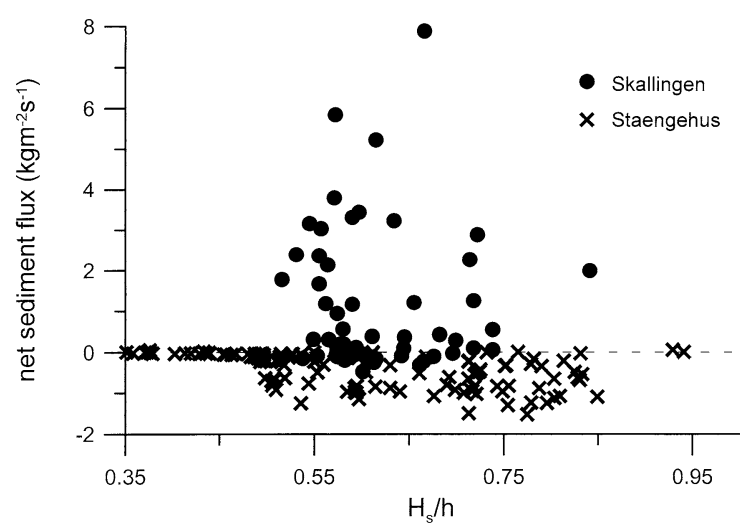

Fig. 5. Measured net sediment fluxes at the lowermost OBS sensor, as a function of local relative wave height, $H_{\mathrm{s}} / h$.

al. (1998) to parameterize cross-shore sediment flux. Each data point represents an instrumental record, i.e. a 34 (or 45)-min time average. The experimental data are not well-constrained. At Skallingen, there was a tendency towards large onshore-directed or smaller offshore-directed sediment fluxes, irrespective of the magnitude of $H_{\mathrm{S}} / h$. At Staengehus the data appear to conform to some extent to the expected pattern, i.e. small transport rates for small values of the relative wave height $\left(H_{\mathrm{s}} / h<\sim 0.5\right)$, trending to offshoredirected transport with increasing incident wave

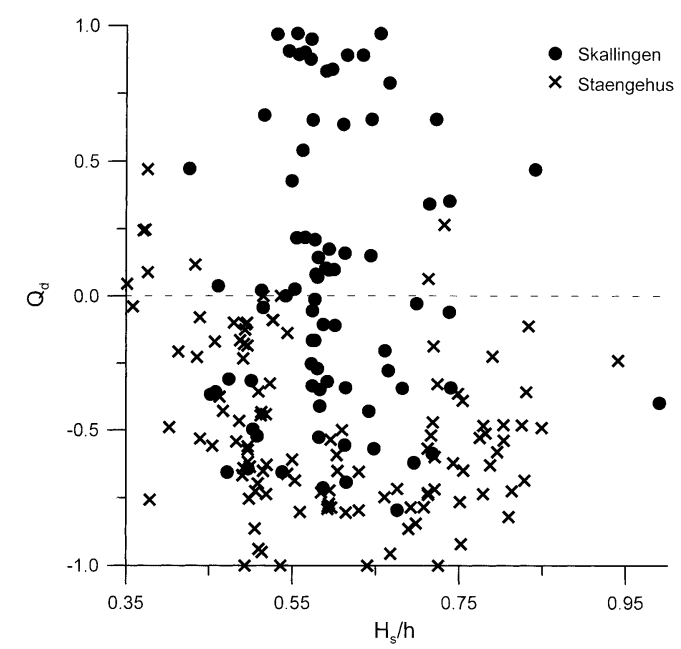

Fig. 6. The non-dimensional sediment flux, $Q_{\mathrm{d}}$, as a function of local relative wave height, $H_{\mathrm{s}} / h$. Only the lowermost exposed backscatter sensor was used. 

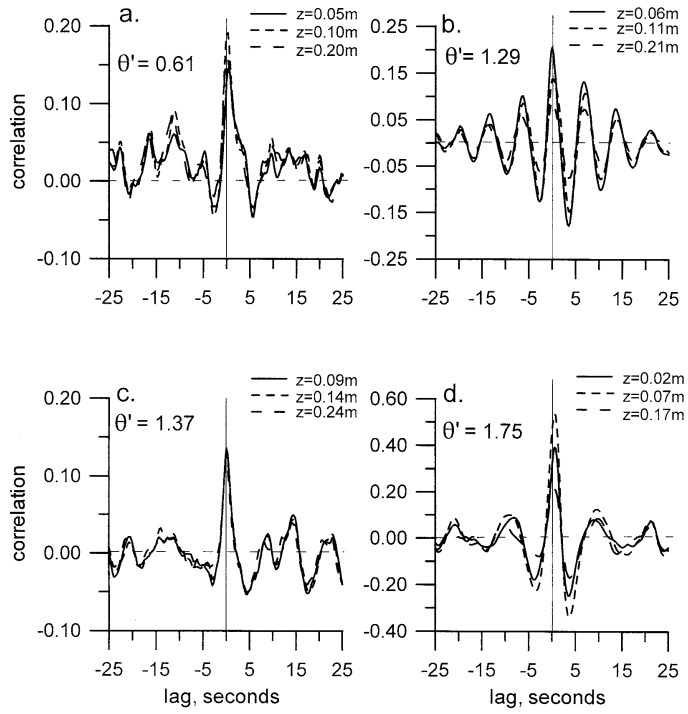

Fig. 7. Examples of cross-correlations of sediment concentrations at three OBS sensor elevations, and high-pass filtered orbital velocity at (a) SK96; station S2, run 301_10, (b) STG98, station S2, run 73c, (c) STG98, station S3, run 73b and (d) SK96, station S2, run 311_01. $\theta^{\prime}$ is the skin-friction Shields parameter due to waves. Note the progressively increasing bed shear stresses and the lack of consistent relationships between cross-correlation and sensor elevation.

dissipation, but then reversing to almost zero net sediment fluxes for the large values of $H_{\mathrm{s}} / h$, which were observed during storm peaks at the crest of the inner bar.

Fig. 6 illustrates the sediment flux index $\left(Q_{\mathrm{d}}\right.$, which ignores infragravity wave contributions) as a function of the relative wave height. Again, a correlation does not appear to exist and any trend is difficult to discern. For the present data set, it must be concluded that $H_{\mathrm{s}} / h$ is not a suitable parameterization/predictor of sediment flux rates or directions under breaking waves.

Instead it may be more informative to consider the actual processes contributing to the net crossshore sediment flux. The flux due to the incident waves must depend at least in part on the maximum cross-correlation $(p)$ between oscillatory velocity at incident wave frequencies and the sediment concentration in the water column, i.e. the strength of the phase coupling (Jaffe et al., 1984). In the case of large positive correlations at small phase lags, the transport by incident waves should be large and in the direction of wave propagation. With increasing phase lags or negative correlations caused, for example, by the existence of bedforms or increasing sensor elevation above the bed, the sediment flux direction may be opposite to the direction of the waves, or much reduced. For the present data set, maximum cross-correlations between cross-shore velocity and sediment concentration at incident wave frequencies were almost consistently positive, except for a few cases under non-breaking or weakly breaking waves. Furthermore, the time lags at maximum correlation were consistently small, usually within $1 \mathrm{~s}$. Fig. 7 illustrates examples of cross-correlations between high-pass filtered orbital velocities and sediment concentrations at all three backscatter levels for a range of computed values of the wave-induced skin-friction Shields parameter $\left(\theta^{\prime}\right)$. Phase lags at correlation peaks are small and, interestingly, they do not consistently increase with sensor elevation above the bed. Furthermore, cross-correlations are not always largest for the lowermost sensor, which suggests a high degree of vertical mixing of the water column within the surf zone.

With a positive correlation maximum at a small time/phase lag (e.g. Fig. 7) we would expect onshore-directed sediment fluxes due to the incident

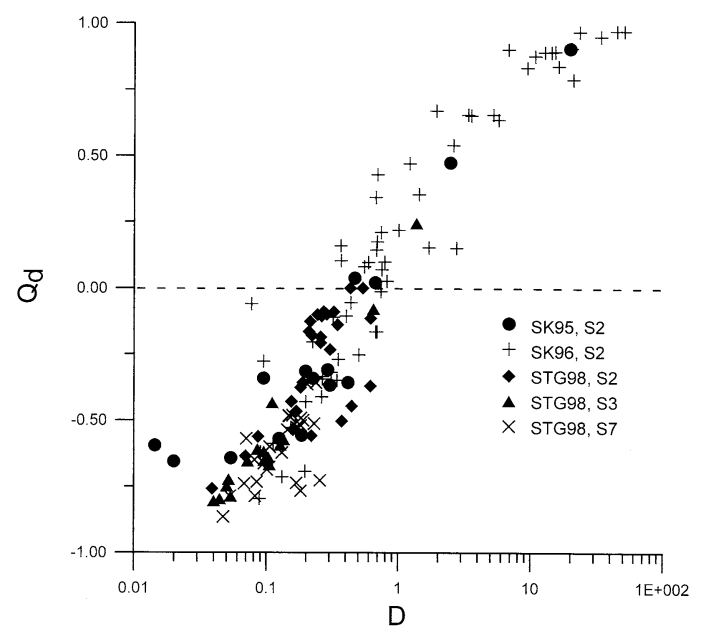

Fig. 8. The non-dimensional sediment transport index, $Q_{\mathrm{d}}$, as a function of $D$. A logarithmic fit through the data has a coefficient of determination of $r^{2}=0.884$. There are 144 degrees of freedom (d.o.f.). 
waves and such fluxes will be enhanced by large incident wave skewnesses $(s$; Eq. 4) and orbital velocities (e.g. Bailard, 1981; Thornton et al., 1996; Gallagher et al., 1998). These three factors should therefore be important to the magnitude of the onshore-directed sediment flux. With respect to the offshore-directed flux, this would be expected to depend upon the strength of the mean current $(\bar{u})$. Consequently, Fig. 8 illustrates $Q_{\mathrm{d}}$ plotted against a non-dimensional parameter $D$ which is expected to reflect the tendency towards onshore or offshore-directed sediment flux. $D$ is given by:

$D=\frac{p \cdot s \cdot u_{\mathrm{rms}}}{|\bar{u}|}$

Again, only the incident wave band contributions are included in the calculations of $p, s$ and $u_{\mathrm{rms}}$ and only data with $H_{\mathrm{s}} / h \geq 0.40$, i.e. breaking waves, have been considered. A logarithmic fit through the data yields a coefficient of determination, $r^{2}=0.884$, and the line of best fit is:

$Q_{\mathrm{d}}=0.285 \ln (D)+0.102$

This result is encouraging as most mechanisms of importance to the net flux seem to be included in Eq. 9 and $D$ appears to be a suitable parameter for determining the balance between incident wave fluxes and fluxes due to the undertow. When $D>\sim 0.7$, the incident waves dominate the sediment flux and the net flux is consequently directed onshore; when $D<\sim 0.7$, mean currents dominate with a resulting offshore-directed net flux.

Despite the good fit, this formulation is presently not well-suited for predictive and/or modelling purposes as incident wave skewness and $u-c$ cross-correlation, in particular, are difficult to determine a priori. Therefore, $s, p$ and $\bar{u}$ were tested against a range of environmental properties, including: (a) the relative wave height $\left(H_{\mathrm{s}} / h\right)$; (b) the surf similarity parameter $\left(I=\beta_{\mathrm{b}} / \sqrt{ }\left(H_{\mathrm{b}} / L_{0}\right)\right.$, where $\beta_{\mathrm{b}}$ is nearshore slope at the breakpoint and $L_{0}$ is deepwater wavelength); (c) the normalized water depth $\left(h / h_{\mathrm{b}}\right)$, where $h_{\mathrm{b}}$ is water depth at the breakpoint; (d) $\Omega\left(=H_{\mathrm{b}} / w_{\mathrm{s}} T\right.$, where $w_{\mathrm{s}}$ is the sediment fall velocity); (e) radiation stress gra- dients $\left(\mathrm{d} H^{2} / \mathrm{d} x\right)$; and (f) the Shields parameter $\left(\theta=\tau / \rho(s-1) g d_{50}\right)$, where $\tau$ is the bed shear stress, $\rho(s-1)$ is the relative sediment density, and $d_{50}$ is the mean sediment grain size (Aagaard and Greenwood, 1999).

\subsection{Undertow velocity}

Undertow velocity $(\bar{u})$ should depend upon local cross-shore radiation stress gradients (which depend on $H^{2}$ ) and scale inversely with local water depth (e.g. Svendsen, 1984). However, local stress gradients are difficult to determine from sensors spaced some $20-40 \mathrm{~m}$ apart and estimated radiation stress gradients had no predictive power with respect to the undertow. Instead, assuming $\gamma=H / h=$ constant over (small) spatial increments, a slope dependency is expected, i.e.:

$\bar{U} \propto \frac{\Delta H^{2} / \Delta x}{h}=\gamma^{2} \frac{\Delta h}{\Delta x}=\gamma^{2} \tan \beta$

where $\beta$ is local slope. Hence, undertow velocities are expected to be larger over steep beaches than on gently sloping beaches (Longuet-Higgins, 1983). Fig. 9 illustrates the functional relationship between undertow velocity and $\left(\gamma_{\mathrm{s}}^{2} \tan \beta\right)$. Data from stations S4 and S5 in the intertidal zone at Skallingen (SK96; Fig. 2) have been included to increase the spread in the data. The nearshore

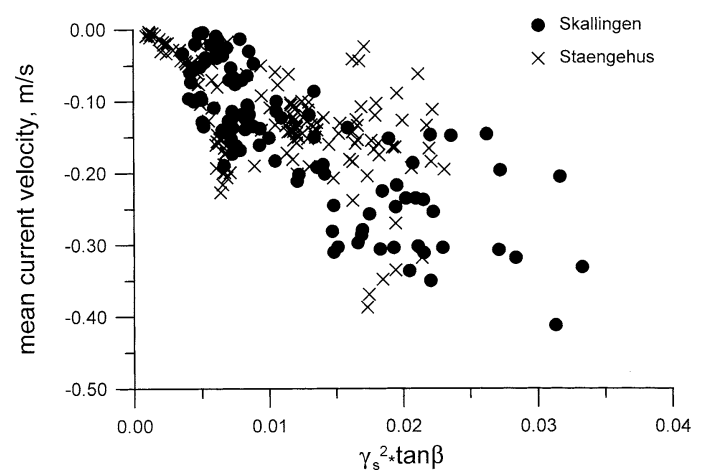

Fig. 9. Mean cross-shore current (undertow) velocity $(\bar{u})$ plotted against the square of the local relative wave height multiplied by the local slope. A linear fit yields $r^{2}=0.494$ with 256 d.o.f. 
slope was determined from the profile segment immediately seaward of the instrument station. While there is a substantial amount of scatter in the data, a linear fit yields a coefficient of determination, $r^{2}=0.494$ which is statistically significant at the $1 \%$ level. The line of best fit is:

$\bar{U}=-9.29\left(\gamma_{\mathrm{s}}^{2} \tan \beta\right)-0.028$

Scatter is expected to be introduced by (a) measurement inaccuracies with respect to the determination of slope; these slopes were calculated from profile surveys before and after storms; (b) lateral mixing of turbulent kinetic energy; at Staengehus, the maximum cross-shore (and longshore) current velocities were often observed over the landward slope of the middle bar instead of at the bar crest (see also e.g. Greenwood and Sherman, 1986); (c) the assumption of spatially constant relative wave heights; $\gamma_{s}$ did vary significantly between neighboring instrument stations, and (d) the assumption of a constant undertow velocity in the vertical and/or the assumption that the recorded velocities were in fact mean undertow velocities. Current meters were typically mounted $0.20-0.30$ $\mathrm{m}$ above the bed which appears to be a reasonable elevation at which to obtain mean undertow velocities (Masselink and Black, 1995). However, even though the water column may have been well-mixed due to the wave breaking, some vertical stratification of current velocities probably existed.

\subsection{Wave skewness}

Incident wave skewness $(s)$ would be expected to depend on offshore wave steepness and some measure of distance relative to the breakpoint, as wave skewness tends to reach a peak at the breakpoint and decrease systematically onshore, at least for planar beaches (e.g. Thornton and Guza, 1989). For barred beaches, Plant et al. (2001) recently obtained a relationship between wave skewness and the local relative wave height. For the present data, the best correlation for $s$ was obtained with the product of the local relative wave height $\left(H_{\mathrm{s}} / h\right)$ and the local relative water depth, defined as $h / h_{\mathrm{b}}$, with $h_{\mathrm{b}}$ being water depth

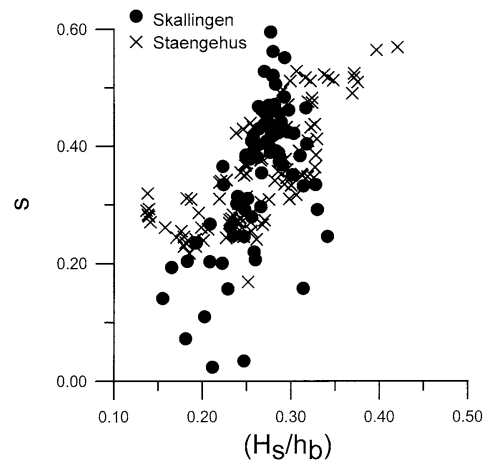

Fig. 10. Incident wave skewness $(s)$ as a function of the local ratio between significant wave height and breaker depth. $r^{2}=0.418 ; 200$ d.o.f. The line of best fit is $s=1.332\left(H_{\mathrm{s}} /\right.$ $\left.h_{\mathrm{b}}\right)+0.004$.

at breaking. At Skallingen where the nearshore slope seaward of the bars is very small, $h_{\mathrm{b}}$ was determined as the water depth at the toe of the outermost bar. It is at this point that strong wave dissipation and deformation of the wave form begins during high-energy conditions, even though depth-limited wave breaking did occur at times seaward of the outer bar. At Staengehus, the bars are steep with deep troughs where incident waves reform. Therefore, $h_{\mathrm{b}}$ was determined from $H_{\mathrm{s}} / 0.35$ with the wave height being estimated from depth-corrected wave records in the troughs between bars. Hence, for stations on the inner bar (S6, S7), $h_{\mathrm{b}}$ was estimated as $H_{\mathrm{s}}(\mathrm{S} 5) / 0.35$ and for stations on the second bar (S2, S3), $h_{\mathrm{b}}$ was estimated as $H_{\mathrm{s}}(\mathrm{S} 1) / 0.35$. A linear regression through all data (Fig. 10) yields a coefficient of determination $r^{2}=0.418$. In all but two cases (not included in the figure), wave skewnesses were positive and thus directed onshore. Scatter in the data is expected at least partly due to the uncertain determination of the breakpoint position. Interestingly, the functional relationship shown in Fig. 10 did not improve when offshore wave steepness was included in the predictor.

\section{6. $u-c$ cross-correlation}

The cross-correlation between fluid velocity and sediment concentration $(p)$ is expected to depend at least in part upon bed configuration. When 

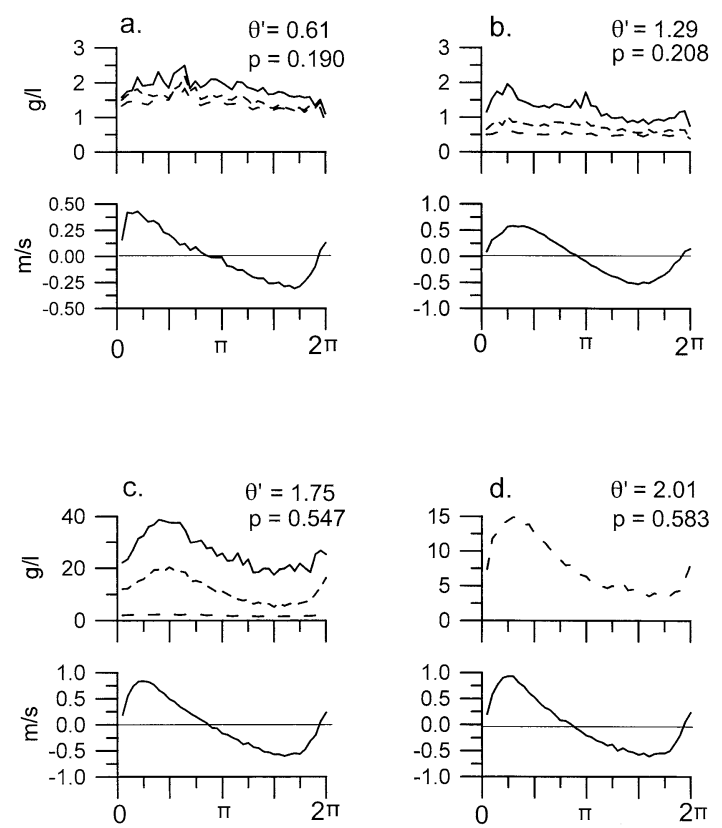

Fig. 11. Phase averages of cross-shore velocity and sediment concentration at the lower (solid), mid (short dashes) and upper (long dashes) OBS sensors for increasing values of the non-dimensional bed shear stresses (the skin-friction Shields parameter due to waves) and $u-c$ cross-correlations. (a) SK96, station S2, run 301_10, (b) STG98, station S2, run 73c, (c) SK96, station S2, run 311_01 and (d) SK96, station S2, run 310_10. Only one OBS sensor was exposed in the last example.

non-dimensional bed shear stresses are small $\left(\theta^{\prime}<\sim 0.2-0.4\right.$; Nielsen, 1992), vortex ripples generally occur at the seabed. Well-developed vortex ripples tend to result in relatively large crosscorrelations between velocity and concentration but with large phase lags, up to $90^{\circ}$ as sediment is ejected from the bedforms at velocity reversals (e.g. Nakato et al., 1977; Osborne and Greenwood, 1993). For increasing bed shear stresses, ripples are washed out and the cross-correlation and phase coupling between $u$ and $c$ are expected to degrade. Flat bed conditions are initiated for $\theta \approx 0.7-1.0$ (Wilson, 1989; Watanabe et al., 1991; Nielsen, 1992). With flat beds, the cross-correlation between velocity and sediment concentration close to the bed again becomes relatively large but with small phase lags (Ribberink and Al-Salem, 1992; Black and Vincent, 2001). Hence, a local minimum in $u-c$ cross-correlation is expected at moderate values of the Shields parameter. Such increasing cross-correlations/phase couplings with increasing bed shear stresses $\left(\theta^{\prime}=0.6-2.0\right)$ are illustrated in Fig. 11 where examples of (demeaned) cross-shore velocity and sediment concentration were phase-averaged over 40 wave-cycle bins. Below the flat bed criterion (Fig. 11a), the pattern of suspended sediment concentration displays a small peak between wave crest and downwards flow reversal and the maximum cross-correlation ( $p$ ) between $u$ and $c$ is small. A phase coupling is not evident. With increasing bed shear stresses, the patterns change to a primary peak at the wave crest and a secondary peak at flow reversal (Fig. 11b). In this example, the computed bed shear stresses exceed the flat bed criterion but the resuspension patterns suggest the presence of some remnant bedforms. For very large bed shear stresses (Fig. 11c,d), the suspended sediment concentration becomes increasingly similar to the velocity trace and $p$ increases significantly. In these cases, the phase coupling between $u$ and $c$ is very strong.

Correlations between orbital velocity and sediment concentration are also generally considered to depend upon the distance between a sensor and the bed (e.g. Ribberink and Al-Salem, 1992; Osborne and Greenwood, 1993; Black and Vincent, 2001). Even though the present data suggest that in the surf zone, this dependency may not be straightforward, at least close to the bed (Fig. 7 ), estimates of $p$ were restricted to data from OBS sensors positioned within approximately $0.10 \mathrm{~m}$ from the bed. Bed elevation was determined at low tide at Skallingen. During SK95, bed level changes were generally small (within $\pm 0.05 \mathrm{~m}$ over tidal cycles at station S2) and the sensors were adjusted at each low tide. During SK96, bed level changes were considerably larger and sensor adjustments were often impossible due to high energy levels. However, at the bar crest (S2), accretion occurred during storms and thus at least one backscatter sensor was within $0.10 \mathrm{~m}$ from the bed. At Staengehus, the bars eroded significantly during storms and the optical sensors were often well away from the bed. Approximate sensor elevations on the middle bar were determined from the bed elevation sensors; only data 
points for which the lower sensor was estimated as being less than $0.10 \mathrm{~m}$ from the bed have been included in the present analysis.

The skin-friction Shields parameter was computed using the non-linear wave-current boundary layer model proposed by Soulsby (1997):

$\theta_{\max }=\frac{\tau_{\max }}{\rho(s-1) g d_{50}}$

The maximum bed shear stress is computed as:

$\tau_{\max }=\left[\left(\tau_{\mathrm{m}}+\tau^{\prime} \cos \phi\right)^{2}+\left(\tau^{\prime} \sin \phi\right)^{2}\right]^{1 / 2}$

where $\phi$ is the angle between the direction of wave incidence and the mean current (computed as $\tan ^{-1}(v / u)$ where demeaned and high-pass filtered, and mean values of the cross-shore and longshore velocity components $(u, v)$ were used, respectively), and $\tau^{\prime}$ is the wave-induced bed shear stress due to grain roughness:

$\tau^{\prime}=1 / 2 \rho f_{\mathrm{w}} u_{\mathrm{s}}^{2}$

$\mathrm{u}_{\mathrm{s}}$ was determined as $2\left(\sigma_{\mathrm{u}}^{2}+\sigma_{\mathrm{v}}^{2}\right)^{1 / 2}$ where $\sigma^{2}$ is orbital velocity variance, and $f_{\mathrm{w}}$ is the wave friction factor:

$f_{\mathrm{w}}=\exp \left[5.213\left(k_{\mathrm{s}} / A\right)^{0.194}-5.977\right]$

(Swart, 1974) and the bed roughness, $k_{\mathrm{s}}$, was set equal to the grain roughness $\left(=2.5 d_{50}\right)$. In Eq. $16, A$ is the orbital diameter near the bed, determined as $A=\left(u_{\mathrm{s}} T_{\mathrm{p}} / 2 \pi\right)$, where $T_{\mathrm{p}}$ is peak spectral wave period. Further, in Eq. 14 the current-induced bed shear stress modified by the wave motion is:

$\tau_{\mathrm{m}}=\tau_{\mathrm{c}}\left[1+1.2\left(\frac{\tau^{\prime}}{\tau^{\prime}+\tau_{\mathrm{c}}}\right)^{3.2}\right]$

(Soulsby, 1997) and the mean current induced bed shear stress in the absence of waves is:

$\tau_{\mathrm{c}}=\rho\left(\frac{\bar{u} \kappa}{\ln \left(z / z_{0}\right)}\right)^{2}$

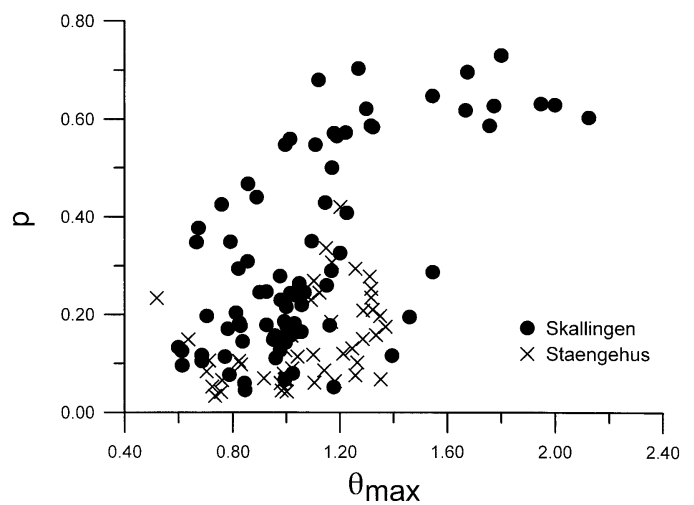

Fig. 12. Correlation between high-pass filtered oscillatory velocity and suspended sediment concentration $(p)$ as a function of the non-dimensional bed shear stress $\left(\theta_{\max }\right)$ under breaking waves in the surf zone. $r^{2}=0.324 ; 124$ d.o.f. Only measurements below $z=0.1 \mathrm{~m}$ have been included.

where $\kappa$ is the von Karman constant $=0.40$ and $z_{0}=k_{\mathrm{s}} / 30=d_{50} / 12$.

The data (Fig. 12) indicate that a significant (at the $1 \%$ level) positive linear correlation $\left(r^{2}=0.324\right)$ existed between the Shields parameter and the $u-c$ cross-correlation for $\theta_{\max }>0.5$ with a line of best fit of $p=0.356 \theta_{\max }-0.130$. Hence, correlation increased with increased flattening of the bed, which is what was expected. The relationship is weak, however, and scatter is undoubtedly introduced by, for example, temporal (undetected) changes in grain size and lags in bedform adjustment to changes in bed shear stress (Davidson et al., 1993), as well as changing sensor elevations (within a $\sim 0.1$-m vertical range).

5.7. A prediction of sediment flux directions in the surf zone

Consequently, substituting $\theta_{\max }$ for $p, H_{\mathrm{s}} / h_{\mathrm{b}}$ for $s$, and $\left(\gamma_{s}^{2} \tan \beta\right)$ for $\bar{u}$, a new parameter, $\Gamma$, is obtained:

$\Gamma=\frac{\theta_{\max } \cdot\left(H_{\mathrm{s}} / h_{\mathrm{b}}\right) \cdot u_{\mathrm{rms}}}{\left(\gamma_{\mathrm{s}}^{2} \cdot \tan \beta\right)}$

Regressing $\Gamma$ against $Q_{\mathrm{d}}$ yields the functional relationship: 


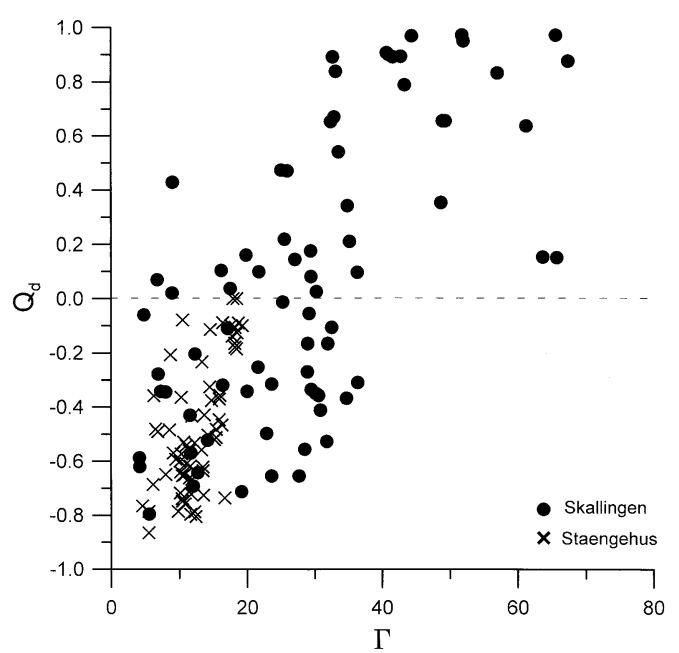

Fig. 13. The non-dimensional sediment transport index, $Q_{\mathrm{d}}$, as a function of the environmental parameter, $\Gamma$. A linear fit yields $r^{2}=0.579 ; 144$ d.o.f.

$Q_{\mathrm{d}}=0.026 \Gamma-0.752$

with a coefficient of determination, $r^{2}=0.579$ (Fig. 13). When $\Gamma$ exceeds approximately 30 , the net suspended sediment transport close to the bed $(z<\sim 0.1 \mathrm{~m})$ tends to be directed landwards, while $\Gamma<30$ results in a tendency for offshore sediment transport. There is significantly more scatter in this relationship than in Fig. 8 which is probably to a large extent due to the difficulties with predicting $p$.

\subsection{Sediment concentrations and net sediment fluxes in the surf zone}

$Q_{\mathrm{d}}$ (Eq. 20) predicts the tendency for onshore or offshore sediment flux, and the magnitude of that tendency. However, to obtain at least a semiquantitative estimate of near-bed $(z<\sim 0.10 \mathrm{~m})$ sediment fluxes, information is required about the concentrations of sediment in the water column. Such concentrations should depend upon elevation above the bed, bed configuration and bed shear stress (e.g. Nielsen, 1992; Black, 1994; Masselink and Pattiaratchi, 2000), as well as wave breaker type (e.g. Kana, 1978; Beach and Sternberg, 1996; Voulgaris and Collins, 2000).
Sediment mixing in the water column can be considered as either a diffusive process, which is generally associated with flat beds, or a convective process which usually occurs when the bed is rippled. In both cases, the vertical distribution of sediment concentration can be formulated as:

$$
C_{z}=C_{0} \exp \left(-\frac{w_{\mathrm{s}} z}{\varepsilon_{\mathrm{s}}}\right)
$$

(e.g. Nielsen, 1984) where $C_{z}$ is sediment concentration at elevation $z, C_{0}$ is a reference concentration near the bed, $w_{\mathrm{s}}$ is the sediment fall velocity, $\varepsilon_{\mathrm{s}}$ is an eddy diffusion coefficient and $z$ is elevation above the seabed. By using the mixing length concept and assuming $\varepsilon_{\mathrm{s}}$ is constant in the vertical, i.e. $l_{\mathrm{s}}=(\mathrm{d} z / \mathrm{d} \ln C)=\left(\varepsilon_{\mathrm{s}} / w_{\mathrm{s}}\right)$, Eq. 21 can be rewritten:

$C_{z}=C_{0} \exp \left(-\frac{z}{l_{\mathrm{s}}}\right)$

This general formulation has been found to work well under a variety of field conditions and with flat as well as rippled beds (e.g. Black, 1994; Green and Black, 1999; Masselink and Pattiaratchi, 2000).

Based on field and laboratory studies, Nielsen (1986) suggested that the reference concentration could be expressed by:

$C_{0}=0.005 \theta^{\prime}{ }_{3}$

where $\theta^{\prime}$ is the skin-friction Shields parameter due to waves $\left(=\tau^{\prime} /\left(p(s-1) g d_{50}\right)\right.$. Turning to the prediction of $C_{0}$ and $l_{\mathrm{s}}$ from the present data sets, the mixing lengths are expected to depend on the processes causing sediment redistribution in the water column. If sediment concentration under breaking waves and with flat beds is mainly a result of diffusion, we would expect the mixing length to scale with the bed shear stress, while in the case of convection, for example due to breaker-induced turbulence, we would expect $l_{\mathrm{s}}$ to scale with the size and intensity of breaker vortices (Nadaoka et al., 1988; Ting, 2001). The characteristics of near-bed breaker vortices associated with various 
breaker types and factors determining their scale are not well known. However, the local relative wave height would appear to be a reasonable first guess as plunging breakers and high breaking intensities occur for large values of the relative wave height (e.g. Wright and Short, 1984; Beach and Sternberg, 1996).

Following Masselink and Pattiaratchi (2000), time-averaged mixing lengths for individual instrument runs were determined from the measurements of sediment concentration at three OBS levels, using $l_{\mathrm{s}}=\mathrm{d} z / \mathrm{d} \ln c$ and computing the line of best fit from the three data points. Only cases when the bed level was recorded and stable between two low tides, or when the bed position was known from the bed elevation sensors were included. Even so, exact OBS sensor elevations relative to the bed must be viewed as crude estimates. There was no statistically significant relationship between the mixing length scale and the bed shear stress $\left(r^{2}=0.094\right)$ but a relationship be-
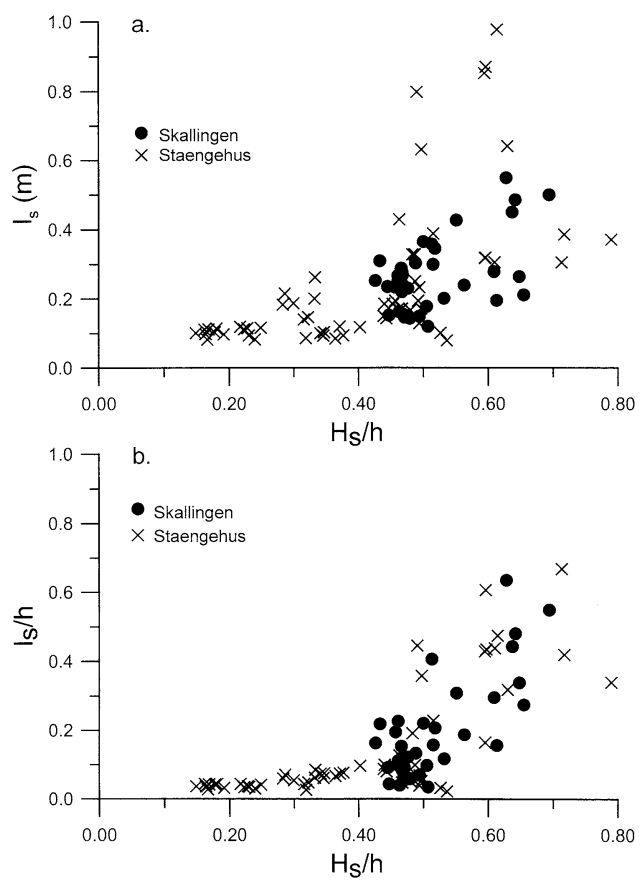

Fig. 14. (a) The vertical mixing length scale, $l_{\mathrm{s}}$, plotted against the local relative wave height, $H_{\mathrm{s}} / h . r^{2}=0.480$; d.o.f. $=96$. (b) The mixing length, scaled by the local water depth, as a function of the local relative wave height. $r^{2}=0.583$; d.o.f. $=96$. tween $l_{\mathrm{s}}$ and $H_{\mathrm{s}} / h$ was obtained (Fig. 14a) with a line of best fit:

$l_{\mathrm{s}}=0.057 \exp \left(2.889\left(H_{\mathrm{s}} / h\right)\right)$

and $r^{2}=0.480$. The data suggest that mixing lengths within the surf zone are on the order of $0.1-1.0 \mathrm{~m}$ which agrees with results from earlier field studies by Black and Rosenberg (1991), Jimenez et al. (1997), Masselink and Pattiaratchi (2000) and Voulgaris and Collins (2000) but are significantly larger than values obtained over flat beds in the laboratory (e.g. Boers, 1999). The mixing length increased as the relative wave height increased from $H_{\mathrm{s}} / h \approx 0.15$ to $H_{\mathrm{s}} / h \approx 0.65$, corresponding to a range from non-breaking conditions through spilling breakers and into the plunging breaker regime. Hence, the relationship between $l_{\mathrm{s}}$ and $H_{\mathrm{s}} / h$ could be due to an increasing diameter of breaker-induced vortices near the bed as the relative wave height increases and/or large vertical velocities associated with plunging breakers.

However, Eq. 24 is dimensional and to nondimensionalize the relationship, $l_{\mathrm{s}}$ was scaled by the local water depth which also resulted in an improved correlation:

$\frac{l_{\mathrm{s}}}{h}=0.012 \exp \left(4.781\left(H_{\mathrm{s}} / h\right)\right)$

and $r^{2}=0.583$, Fig. 14b. The reason for the improved correlation may be that the diameter of breaker vortices is depth-limited, particularly in shallow water where the relative wave height is maximum. There was no significant correlation between $l_{\mathrm{s}}$ and the local value of the surf scaling parameter as was observed by Voulgaris and Collins (2000).

Subsequently, $C_{0}$ was computed from Eq. 22 using the obtained estimates of $l_{\mathrm{s}}$. In Fig. 15, $C_{0}$ is plotted against the Shields parameter. The dimensional form of $C_{0}$ has been chosen, using $\rho_{\mathrm{s}}=2650 \mathrm{~kg} / \mathrm{m}^{3}$ and a pore space factor $a^{\prime}=0.6$. In Fig. 15a, all available computed reference concentrations have been plotted against $\theta^{\prime}$ in order to compare the data with the original formulation (Eq. 23). While Eq. 23 does pass through the cluster of data points, there is a large amount of 


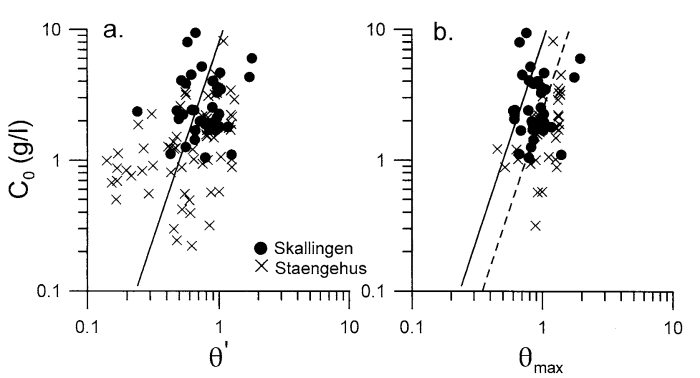

Fig. 15. (a) The near-bed reference concentration $\left(C_{0}\right)$ plotted against the skin-friction Shields parameter due to waves $\left(\theta^{\prime}\right)$. The solid line represents $C_{0}=0.005 \theta^{\prime 3}$. (b) $C_{0}$ plotted against $\theta_{\max }$ and for surf zone conditions only. The solid line represents $C_{0}=0.005 \theta_{\max }^{3}$ and the dashed line is $C_{0}=0.0015$ $\theta_{\max }^{3}$.

scatter. The majority of the scatter may be due to measurement inaccuracies with respect to $z$ and $l_{\mathrm{s}}$ and some may be due to the existence of bedforms and the resulting flow acceleration at ripple crests which will increase $\theta$ and hence reference concentrations (e.g. Green and Black, 1999).

In Fig. 15b, only data points obtained from the surf zone (and with $\theta^{\prime}>0.8$, i.e. flat bed conditions) are included. Under conditions with breaking waves and in the presence of strong currents, $\theta_{\max }$ (Eq. 12) is probably a more appropriate measure of the actually occurring bed shear stresses than $\theta^{\prime}$ and Fig. 15b suggests that for high-energy surf zones, $C_{0}=0.0015 \theta_{\max }^{3}$ might be a better approximation than Eq. 23.

Having found reasonable predictors for nearbed sediment concentrations, these are combined with the sediment flux index in order to obtain a first approximation of net suspended sediment fluxes $\left(Q_{\mathrm{s}}\right)$ in the near-bed layer $(z<\sim 0.1 \mathrm{~m})$ under surf zone conditions across nearshore bars:

$$
\begin{aligned}
& Q_{\mathrm{s}}=(0.026 \Gamma-0.752) \times \\
& 0.0015 \rho_{\mathrm{s}} a^{\prime} \theta_{\max }^{3} \exp \left(-\frac{z}{0.012 \exp \left(4.781\left(H_{\mathrm{s}} / h\right)\right)}\right)
\end{aligned}
$$

where the dimensional form of the reference concentration has been used and $Q_{\mathrm{s}}$ has the dimension of $\mathrm{kg} / \mathrm{m}^{2} / \mathrm{s}$.

\section{Discussion}

The process-based formulation of the sediment transport direction in the near-bed layer $(z<0.1 \mathrm{~m})$, which has been proposed here (Fig. 8), seems to capture the majority of the mechanisms which are responsible for cross-shore transport of suspended sediment due to incident waves and undertows. The results indicate that the net transport direction depends upon the maximum cross-correlation between orbital velocity and sediment concentration $(p)$, the incident wave skewness $(s)$ and the mean current speed $(\bar{u})$. The degree of scatter in Fig. 8 is relatively small given the wide range of possible measurement errors (e.g. instrument offset errors, errors due to varying sensor elevation above the bed, temporal changes in sediment grain size, etc.).

Significantly more scatter was introduced when $Q_{\text {d }}$ was instead correlated with a set of predictable hydrodynamic, textural and bathymetric properties (Eqs. 19 and 20), even though correlations were all statistically significant at the $1 \%$ level (Figs. 9, 10 and 12). As expected, the incident wave skewness depended upon local relative water depth and wave height, the $u-c$ cross-correlation depended upon the non-dimensional bed shear stress probably through a relationship between the latter and bed configuration, while the mean current velocity depended upon local relative wave height and bed gradient. However, factors other than $\theta_{\max }, H_{\mathrm{s}} / h_{\mathrm{b}}$ and $\left(\gamma^{2} \tan \beta\right)$ are clearly important to $p, a$ and $\bar{u}$. Some of the scatter in the correlations may be due to the fact that $f_{\mathrm{w}}$, and $\theta_{\max }$ were computed using the plane-bed (grain) roughness, $k_{\mathrm{s}}=2.5 \mathrm{~d}_{50}$. The calculated values of $\theta_{\max }$ for surf zone conditions ranged between 0.61 and 2.12 and post-vortex ripples may have occurred occasionally, especially in the lower end of this range, increasing the bed roughness. Furthermore, large sediment concentrations which are expected to increase the roughness (e.g. Glenn and Grant, 1987) were not taken into account.

Nevertheless, Eqs. 19 and 20 suggest that relatively large water depths with moderate wave breaking on gentle slopes, and large bed shear stresses should promote landward sediment transport due to incident waves. However, landward 
transports can occur even with saturated wave breaking (Figs. 3 and 4) if bed shear stresses are sufficiently large and slopes sufficiently small. On the other hand, small water depths and intense wave breaking on steep slopes should promote seaward transport. The former situation is expected to occur typically some distance away from the shoreline and/or at high tide/storm surges during high wave energy events and enhanced by strong longshore currents; the latter situation will typically occur in the inner part of the surf zone.

Surprisingly, no direct functional dependency between transport direction and sediment grain size and/or sediment fall velocity seemed to exist in the present data set. Obviously, this might be because the spectrum of grain sizes was relatively narrow and grain size effects may have been overshadowed by other mechanisms. However, the non-dimensional bed shear stress is inversely dependent upon sediment grain size and additionally, steep slopes which enhance the undertow velocity generally occur for coarser grain sizes. Hence, within the surf zone of relatively coarsegrained beaches there should be a tendency for negative values of $Q_{\mathrm{d}}$ and a propensity for offshore sediment transport while the opposite should be the case for relatively fine grain sizes which are usually associated with gently sloping beaches.

This proposed parameterization would be capable of predicting bar formation/location as a function of sediment transport convergences within the surf zone without resorting to mechanisms such as standing infragravity waves. Bar position would be determined by a balance between the effects of bed shear stress and water depth, generally decreasing onshore (except for troughs between bars), and the effect of relative wave height which is typically increasing in the onshore direction. It is clear, however, that this balance can be perturbed by the velocity field set up by infragravity waves, the effects of which are not included in the model. Consequently, the formulation is not expected to be valid when infragravity waves play a predominant role in the suspension and transport of sediment, e.g. in very shallow water depths close to the shoreline.
The above concept could also provide an explanation for the frequently observed approach to equilibrium conditions during storms, or indeed the occurrence of an 'equilibrium profile'. Often beaches erode significantly at the beginning of a storm, or storm sequence (through offshore sediment transport), while relatively limited change occurs later on (e.g. Lee et al., 1998). According to the present model, the reason could be that as sediment is eroded from the intertidal beach or from the bar crest and deposited on seaward slopes, the overall beach profile is flattened and undertow velocities should decrease. Subsequently, $Q_{\mathrm{d}}$ (and $Q_{\mathrm{s}}$ ) could increase and approach a balance where $Q_{\mathrm{d}} \approx 0$.

The formulation of the sediment transport index (Eqs. 19 and 20) is based on the assumption that cross-correlations between oscillatory velocity and sediment concentration are constant in the near-bed layer $(z<0.10 \mathrm{~m})$ and that phase lags are negligible. Surf zone data from these two field sites do suggest that under strongly breaking waves, there is a high degree of vertical mixing in the water column. Phase lags between orbital velocity and sediment concentration were consistently found to be small and did not significantly increase with elevation relative to the bed, and cross-correlations did not exhibit any consistent decrease with increasing elevation (Fig. 7).

The model for the sediment concentration profile, proposed by Nielsen (1984), Eq. 21, has been applied for surf zone conditions. The present data suggest that mixing length scales are significantly larger within the surf zone compared to locations outside the breakpoint, and the magnitudes are in accordance with previous findings by Black and Rosenberg (1991) and Masselink and Pattiaratchi (2000). Again, no direct dependency was found between the mixing length and sediment fall velocity, mean grain size or local bed shear stress. Thus, there appears to be a real difference in the sediment resuspension mechanisms over flat beds within and outside the surf zone; in the latter case, sediment suspension is primarily accomplished by turbulent diffusion close to the bed with small mixing length scales (e.g. Fredsøe and Deigaard, 1992; Black and Vincent, 2001), while within high-energy surf zones, mixing length 
scales are probably increased significantly by the generation of breaker-induced turbulent vortices and possibly large vertical velocities just prior to breaking.

The expression for near-bed reference concentrations suggested by Nielsen (1984) seems to work reasonably well for high-energy surf zone conditions. Even with the poor control on exact sensor elevation, the data points were relatively well constrained by the expression (Eq. 23) and displayed the expected cubic relationship with the non-dimensional bed shear stress. However, when waves coexist with strong currents, for example within the surf zone, the wave-induced bed shear stresses $\left(\theta^{\prime}\right)$ in isolation may not be an adequate representation of true bed shear stresses as the non-linear interaction between waves and currents in the near-bed layer significantly increases shear stress at the bed (e.g. Grant and Madsen, 1979). Accordingly, when using $\theta_{\max }$ instead of $\theta^{\prime}$, the constant of proportionality in Eq. 23 needs to be reduced by approximately a factor of three.

Finally, the sediment transport index was combined with the parameterization of the sediment concentration profile under breaking waves into a formulation of suspended sediment transport rates in the near-bed layer (Eq. 26). There is ample scope for improvement of this model and additional work is required to incorporate infragravity fluxes and their spatial and temporal variability. Furthermore, the model is restricted to the near-bed layer and even though the majority of suspended sediment transport probably does occur close to the bed, the high degree of vertical mixing observed here shows that significant amounts of sediment are suspended to large elevations above the seabed. However, a prediction of sediment transport at higher elevations would require a parameterization of $p$ as a function of elevation which would probably have to rely on prototype scale laboratory measurements as the exact determination of bed elevation under field conditions is extremely difficult.

In general, an improved understanding of $p$ and its dependency on factors other than $\theta$ (e.g. bedforms (active and relict) and large sediment concentrations) are required. The poor prediction of $p$ (Fig. 12) is probably one of the main sources of increased scatter in Fig. 13 relative to Fig. 8.

Improved predictions of incident wave skewnesses in barred surf zones as well as a parameterization of horizontal and vertical undertow structure would also enhance the validity of the model. The latter would require a determination of horizontal and vertical mixing due to turbulent incident wave bores. Finally, the prediction of $l_{\mathrm{s}}$ (Eq. 25 ) is not well-constrained and obviously factors other than the relative wave height and water depth are of significant importance to the mixing length scale in the surf zone. Investigation of important additional mechanisms would in all likelihood require detailed numerical modelling and/ or large scale laboratory measurements under breaking waves. Regardless of these reservations, however, the proposed model appears to provide a reasonable first approximation to near-bed suspended sediment transport across nearshore bars in the surf zone.

\section{Conclusions}

In this paper, a relationship between sediment flux directions in the near-bed layer and a limited number of hydro- and sediment dynamic parameters was obtained. These parameters included wave orbital velocity and skewness, the cross-correlation between orbital velocity and sediment concentration, and the undertow velocity. However, these parameters are difficult to predict and were substituted with a number of more easily obtainable hydrodynamic, sedimentary and bathymetric parameters. While the degree of predicting skill degraded, as would have been expected, the obtained relationships were still significant at the $1 \%$ level.

The model predicts onshore-directed sediment transports for large bed shear stresses in relatively deep water occurring on gently sloping beaches. Such characteristics are associated with large wave orbital velocities and asymmetries, large bed shear stresses and relatively weak cross-shore currents. With increased breaking intensity in shallow water and for relatively steep nearshore slopes, undertows increase and the sediment 
transport becomes offshore-directed. The magnitude of the sediment transport depends on sediment concentrations in the water column; these were found to depend upon bed shear stress and (probably) the diameter of breaker-induced vortices.

\section{Acknowledgements}

This study was supported by the Danish Natural Sciences Research Council through Grant no. 9701836 and 11-0925. Jørgen Nielsen, Ulf Thomas, Rasmus Nielsen and Kalle Kronholm provided invaluable field assistance. We would also like to thank the North Zealand Forest District for giving us permission to work at Staengehus. Parts of this paper were written up while the first author was a visiting academic at the Department of Earth Sciences, University of Waikato. We appreciate the comments made by the reviewers on an earlier version of this manuscript.

\section{References}

Aagaard, T., 2001. Modulation of surf zone processes on a barred beach due to changing water levels. J. Coast. Res. 17.

Aagaard, T., Greenwood, B., 1994. Suspended sediment transport and the role of infragravity waves in a barred surf zone. Mar. Geol. 118, 23-48.

Aagaard, T., Greenwood, B., 1999. Directionality of crossshore sediment transport in the surf zone under high-energy conditions. Proc. Coastal Sediments '99, ASCE, pp. 10031018.

Aagaard, T., Nielsen, J., Greenwood, B., 1998. Suspended sediment transport and nearshore bar formation on a shallow intermediate-state beach. Mar. Geol. 148, 203-225.

Aagaard, T., Greenwood, B., Nielsen, J., 2001. Bed level changes and megaripple migration on a barred beach. J. Coast. Res., SI 34.

Bailard, J.A., 1981. An energetics total load sediment transport model for a plane sloping beach. J. Geophys. Res. 86, 10938-10954.

Beach, R.A., Sternberg, R.W., 1991. Infragravity driven suspended sediment transport in the swash, inner and outer surf zones. Proc. Coastal Sediments '99, ASCE, pp. 114-128.

Beach, R.A., Sternberg, R.W., 1996. Suspended-sediment transport in the surf zone: Response to breaking waves. Cont. Shelf Res. 16, 1989-2003.

Birkemeier, W.A., Long, C.E., Hathaway, K.K., 1997. Delilah,
Duck94 and SandyDuck: Three nearshore field experiments. Proc. 25th Coast. Eng. Conf., ASCE, pp. 4052-4065.

Black, K., 1994. Suspended sediment load during an asymmetric wave cycle over a plane bed. Coast. Eng. 23, 95-114.

Black, K., Rosenberg, M.A., 1991. Suspended sediment load at three timescales. Proc. Coastal Sediments '91, ASCE, pp. 313-327.

Black, K.P., Vincent, C.E., 2001. High-resolution field measurements and numerical modelling of intra-wave sediment suspension on plane beds under shoaling waves. Coast. Eng. 42, 173-197.

Boers, M., 1999. Effect of wave breaking and bed friction on suspended sediment concentration. Proc. Coastal Sediments '99, ASCE, pp. 209-224.

Davidson, M.A., Russell, P.E., Huntley, D.A., Hardisty, J., 1993. Tidal asymmetry in suspended sand transport on a macrotidal intermediate beach. Mar. Geol. 110, 333-353.

Elgar, S., Gallagher, E.L., Guza, R.T., 2001. Nearshore sandbar migration. J. Geophys. Res. 106, 11623-11627.

Fredsøe, J., Deigaard, R., 1992. Mechanics of Coastal Sediment Transport. World Scientific, Singapore, 369 pp.

Gallagher, E.L., Elgar, S., Guza, R.T., 1998. Observations of sand bar evolution on a natural beach. J. Geophys. Res. $103,3203-3215$.

Glenn, S.M., Grant, W.D., 1987. A suspended sediment stratification correction for combined wave and current flows. J. Geophys. Res. 92, 8244-8264.

Grant, W.D., Madsen, O.S., 1979. Combined wave and current interaction with a rough bottom. J. Geophys. Res. 84 , 1797-1808.

Grasmeijer, B.T., van Rijn, L.C., 1999. Breaker bar formation and migration. Proc. 26th Coastal Engineering Conference, ASCE, pp. 2750-2758.

Grasmeijer, B.T., Chung, D.H., van Rijn, L.C., 1999. Depthintegrated sand transport in the surf zone. Proc. Coastal Sediments '99, ASCE, pp. 325-340.

Green, M.O., 1999. Test of sediment initial-motion theories using irregular-wave field data. Sedimentology 46, 427-442.

Green, M.O., Black, K.P., 1999. Suspended-sediment reference concentration under waves: Field observations and critical analysis of two predictive models. Coast. Eng. 38, 115-141.

Greenwood, B., Davidson-Arnott, R.G.D., 1979. Sedimentation and equilibrium in wave-formed bars: A review and case study. Can. J. Earth Sci. 16, 312-332.

Greenwood, B., Sherman, D.J., 1986. Longshore current profiles and lateral mixing across the surf zone of a barred nearshore. Coast. Eng. 10, 149-186.

Huntley, D.A., Hanes, D.M., 1987. Direct measurement of suspended sediment transport. Proc. Coastal Sediments '87, ASCE, pp. 723-737.

Jaffe, B.E., Sternberg, R.W., Sallenger, A.H., 1984. The role of suspended sediment in shore-normal beach profile changes. Proc. 19th Coast. Eng. Conf., ASCE, pp. 1983-1996.

Jimenez, J.A., Rivero, F.J., Sanchez-Arcilla, A., Gracia, V., Rodriguez, A., 1997. Suspended sediment mixing in the surf zone. Proc. 25th Coast. Eng. Conf., ASCE, pp. 4098 4110. 
Kana, T.W., 1978. Surf zone measurements of suspended sediment. Proc. 16th Coast. Eng. Conf., ASCE, pp. 1725-1743.

Komar, P.D., 1998. Beach Processes and Sedimentation, 2nd edn. Prentice-Hall, Englewood Cliffs, NJ, 544 pp.

Larson, M., Kraus, N.C., 1989. SBEACH: Numerical model for simulating storm-induced beach change. CERC TR 89-9, $256 \mathrm{pp}$.

Lee, G.H., Nicholls, R.J., Birkemeier, W.A., 1998. Storm-driven variability of the beach-nearshore profile at Duck, North Carolina, USA, 1981-1991. Mar. Geol. 148, 163-177.

Longuet-Higgins, M.S., 1983. Wave set-up, percolation and undertow in the surf zone. Proc. R. Soc. London A390, 283-291.

Masselink, G., Black, K.P., 1995. Magnitude and cross-shore distribution of bed return flow measured on natural beaches. Coast. Eng. 25, 165-190.

Masselink, G., Pattiaratchi, C., 2000. Tidal asymmetry in sediment resuspension on a macrotidal beach in northwestern Australia. Mar. Geol. 163, 257-274.

Miller, H.C., Smith, S.J., Hamilton, D.G., Resio, D.T., 1999. Cross-shore transport mechanisms during onshore bar migration. Proc. Coastal Sediments '99, ASCE, pp. 1065-1080.

Nadaoka, K., Ueno, S., Igarashi, T., 1988. Sediment suspension due to large eddies in the surf zone. Proc. 22nd Coast. Eng. Conf., ASCE, pp. 1646-1660.

Nakato, T., Locher, F.A., Glover, J.R., Kennedy, J.F., 1977. Wave entrainment of sand from rippled beds. J. Waterw. Port Coast. Ocean Div. ASCE 103, 83-99.

Nielsen, P., 1984. Field measurements of time-averaged suspended sediment concentrations under waves. Coast. Eng. $8,51-72$.

Nielsen, P., 1986. Suspended sediment concentrations under waves. Coast. Eng. 10, 23-31.

Nielsen, P., 1992. Coastal Bottom Boundary Layers and Sediment Transport. World Scientific, Singapore, 324 pp.

Osborne, P.D., Greenwood, B., 1992. Frequency dependent cross-shore suspended sediment transport. 2. A barred shoreface. Mar. Geol. 106, 25-51.

Osborne, P.D., Greenwood, B., 1993. Sediment suspension under waves and currents: Time scales and vertical structure. Sedimentology 40, 599-622.

Plant, N.G., Ruessink, B.G., Wijnber, K.M., 2001. Morphologic properties derived from a simple cross-shore sediment transport model. J. Geophys. Res. 106, 945-958.

Rakha, K.A., Deigaard, R., Brøker, I., 1997. A phase-resolving cross-shore sediment transport model for beach profile evolution. Coast. Eng. 31, 231-261.

Ribberink, J.S., Al-Salem, A.A., 1992. Time-dependent sediment transport phenomena in oscillatory boundary-layer flow under sheet flow conditions. Delft Hydraulics Data Report H840.20, Part VI, Delft.

Ridd, P.V., 1992. A sediment level sensor for erosion and siltation detection. Est. Coast. Shelf Sci. 35, 353-362.

Ruessink, B.G., Houwman, K.T., Hoekstra, P., 1998. The systematic contribution of transporting mechanisms to the cross-shore sediment transport in water depths of 3 to $9 \mathrm{~m}$. Mar. Geol. 152, 295-324.
Ruessink, B.G., Terwindt, J.H.J., 2000. The behaviour of nearshore bars on the time scale of years: A conceptual model. Mar. Geol. 163, 289-302.

Russell, P.E., 1993. Mechanisms for beach erosion during storms. Cont. Shelf Res. 13, 1243-1265.

Russell, P.E., Huntley, D.A., 1999. A cross-shore transport 'shape function' for high energy beaches. J. Coast. Res. 15, 198-205.

Sallenger, A.H., Holman, R.A., 1985. Wave energy saturation on a natural beach with variable slope. J. Geophys. Res. 90, 11939-11944.

Schoonees, J.S., Theron, A.K., 1995. Evaluation of ten crossshore sediment transport/morphological models. Coast. Eng. $25,1-41$.

Shepard, F.P., 1950. Beach cycles in Southern California. U.S Army Corps of Engineers, Beach Erosion Board, Techn. Memo 15, 31 pp.

Soulsby, R., 1997. Dynamics of Marine Sands. Telford, London, $249 \mathrm{pp}$.

Svendsen, I.A., 1984. Mass flux and undertow in a surf zone. Coast. Eng. 8, 347-365.

Swart, D.H., 1974. Offshore sediment transport and equilibrium beach profiles. Delft Hydrol. Lab. Publ. 131, 247 pp.

Thornton, E.B., Guza, R.T., 1982. Energy saturation and phase speeds measured on a natural beach. J. Geophys. Res. 87, 9499-9508.

Thornton, E.B., Guza, R.T., 1989. Wind wave transformation. In: Seymour, R.J. (Ed.), Nearshore Sediment Transport. Plenum Press, New York, pp. 137-171.

Thornton, E.B., Humiston, R.T., Birkemeier, W.A., 1996. Bar/ trough generation on a natural beach. J. Geophys. Res. 101, 12097-12110.

Ting, F.C.K., 2001. Laboratory study of wave and turbulence velocities in a broad-banded irregular wave surf zone. Coast. Eng. 43, 183-208.

Van Rijn, L.C., 1993. Principles of Sediment Transport in Rivers, Estuaries and Coastal Seas. Aqua Publications, Amsterdam.

Van Rijn, L.C., 1998. Principles of Coastal Morphology. Aqua Publications, Amsterdam.

Van Rijn, L.C., Ruessink, B.G., Grasmeijer, B.T., 1999. Generation and migration of nearshore bars under non- to macrotidal conditions. Proc. Coastal Sediments '99, ASCE, pp. $463-478$.

Voulgaris, G., Collins, M.B., 2000. Sediment resuspension on beaches: Response to breaking waves. Mar. Geol. 167, 167187.

Watanabe, A., Shimizu, T., Kondo, K., 1991. Field application of a numerical model of beach topography change. Proc. Coastal Sediments '91, ASCE, pp. 1814-1828.

Wilson, K.C., 1989. Mobile bed friction at high shear stress. J. Hydraul. Eng. 115, 825-830.

Wright, L.D., Guza, R.T., Short, A.D., 1982. Dynamics of a high energy dissipative surf zone. Mar. Geol. 45, 41-62.

Wright, L.D., Short, A.D., 1984. Morphodynamic variability of beaches and surf zones: A synthesis. Mar. Geol. 56, 92118. 